oceans have enabled the dispersal of human civilizations across Earth. Best of all, the book reads like a good story because of the autobiographical way in which Ebbesmeyer and Scigliano lead the reader through.

My own path through oceanography has been similar to Ebbesmeyer's. We both worked on similar problems; from slabs of water and their mixing to tracking spills, dead bodies and plastic ducks. In the 1970s and 1980s, oceanography involved more exploration and pure experimentation than is typical today - it was romantic and fun. We get more out of marine science now, using technological tools such as satellites, supercomputers, robotic drifters and acoustic probes. But we have also inherited a bureaucracy of targets, cost allocations and concerns over health and safety, and this change in culture comes through in Ebbesmeyer's story. Concern for safety is no bad thing. But picture the scene if we were to start oceanography from scratch today - "Yes, we're going out in very deep water with 10-metre waves, in a small metal container while operating high-voltage equipment and explosives." We would be banned.

Whether you want to learn more about how the oceans tick or how we are affecting our environment, or to reminisce about science not being what it used to be, this is a very enjoyable, if at times dark, book. And I never did have to resort to the in-flight movie.

Simon Boxall is a lecturer in oceanography at the National Oceanography Centre, University of Southampton, Southampton SO14 3ZH, UK. e-mail: simon.boxall@noc.soton.ac.uk

\section{Cooking debate goes off the boil}

\section{Catching Fire: How Cooking Made Us \\ Human \\ by Richard Wrangham \\ Basic Books: 2009. 320 pp. \$26.95}

Richard Wrangham's new book is an expansion of a provocative hypothesis about human history that he and his colleagues first published in 1999. Cleverly evoking anthropologist Claude Lévi-Strauss's work The Raw and the Cooked, the article was entitled 'The Raw and the Stolen: Cooking and the Ecology of Human Origins.' Wrangham restates his hypothesis concisely and elegantly at the outset of Catching Fire:

"I believe the transformative moment that gave rise to the genus Homo, one of the great transitions in the history of life, stemmed from the control of fire and the advent of cooked meals. Cooking increased the value of our food. It changed ... our social lives. It made us into consumers of external energy and thereby created an organism with a new relationship to nature, dependent on fuel."

The primary criticism of the cooking hypothesis, as it was first published, centred on the lack of convincing evidence that cooking began about 2 million years ago in Africa. Wrangham, a biological anthropologist at Harvard University, attributes the origin of the large-brained Homo erectus and its geographic expansion out of Africa to the invention of a new mode of preparing tubers that greatly enhanced digestibility and nutritional benefits. The hypothesis was sceptically received in 1999; commentators used the phrases "half-baked" and "Just-so story”. After an additional ten years of research, I hoped Wrangham would present a stronger argument. He does not.

The oldest credible evidence of controlled fire is around 790,000 years old, from a site at Gesher Benot Yaaqov in Israel. Here, burned flint fragments were clustered, suggesting the use of hearths. But burned seeds and wood, also present, were not clustered near the hearths or one another. So apart from the burned flint, the evidence for controlled fire at this site is equivocal, as is all such evidence before about 250,000 years ago.

The lack of evidence is daunting. If one individual and his descendents made a fire once a week for a million years, they should have left the remains of some 50,000,000 fires. "Evidence of humans controlling fire is hard to recover from early times," Wrangham says.

The main ingredient of his hypothesis is, succinctly, potatoes. Early hominins used cooked tubers and underground storage organs of plants as an important fall-back food. Tubers were underused by other species because they require digging and cooking for maximum benefit.

But Wrangham runs afoul of the evidence here too. Stone tool assemblages from before 2 million years ago include cores, small sharp flakes for cutting and hammer stones for producing flakes and for pounding. Overwhelming evidence shows that these stone tools were used to cut up dead animals. Cut marks and percussion marks from breaking open long bones to extract marrow occur on hundreds of fossils. In 2002, Eric Hoberg showed that human-specific tapeworms are most closely related to tapeworms that infest the carnivores with which early Homo competed for carcasses nearly 2 million years ago. There is much evidence that early hominins ate meat, but little to show that their tools

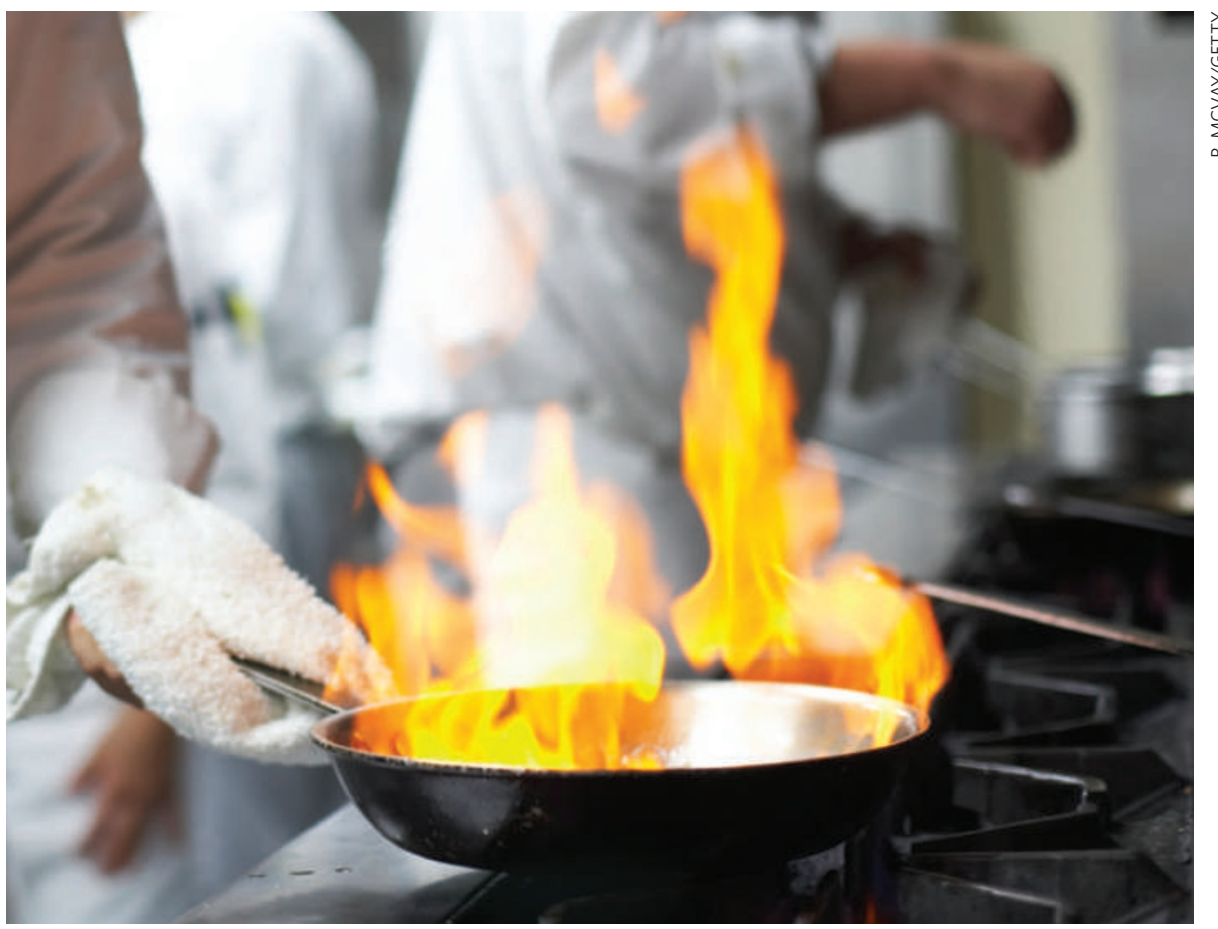

Learning how to control fire for cooking might have helped early hominins develop bigger brains. 
were used on plants, and none that there were cooking fires or digging sticks at that time.

Wrangham interprets various anatomical traits of humans - small mouths, small gapes, weak jaws, small teeth and a short digestive system - as adaptations to eating soft, highdensity food with little fibre in it. Are these truly adaptations to cooked food?

In 1995, Leslie Aiello and Peter Wheeler suggested that increased meat-eating caused the increase in hominin brain size about 2 million years ago. They proposed that a meatrich diet accessed with stone tools permitted guts to become smaller, freeing up energy for brain growth. Primates with smaller guts consistently have larger brains, and humans are the extreme case of small guts and large brains, they said. Their hypothesis is compelling.

Wrangham argues that lumps of raw meat are difficult to digest and protein intake must be balanced with carbohydrate intake. Carbohydrates can be obtained from fat, marrow, brains, fruits and nuts, and are abundant in foods happily eaten raw by baboons, chimps and warthogs - such as corms, rhizomes and tubers of savannah plants - so Wrangham's dismissal of these sources of carbohydrates is unpersuasive.

Fire has other advantages, Wrangham observes. Sleeping on the ground at night was dangerous for hominins and a fire kept predators away. True, but antelopes sleep on the ground and have not yet invented fire or cooking.

Wrangham's analysis of the effect of cooking on humans is stronger. Cooking may have promoted a division of labour by sex. Large, prized food items hunted by males were taken home and shared, as were large vegetable items, such as tubers, gathered by females. Because females have babies, they often took on the tasks of foraging for staple vegetable foods and cooking.

Pair-bonding is another component of Wrangham's scenario. It ensures that the male hunter will have something to eat if he returns empty-handed, and reassures him that the baby he feeds is his. Pair-bonding assures the female gatherer that someone will contribute high-protein items to her baby. Because fires are visible for long distances, they may draw food thieves, so pair-bonding also gives protection to the cooks.

Wrangham's thinking about the effect of food choices on society is interesting, but his attempt to superimpose his hypothesis on to the early fossil and archaeological record is unconvincing.

Pat Shipman is professor of anthropology at Penn State University, University Park, Pennsylvania 16802, USA.

e-mail: pls10@psu.edu

\section{Our changing body image}

\section{Assembling Bodies: Art, Science and Imagination \\ Museum of Archaeology and Anthropology, Cambridge, UK Until November 2010}

A gleaming transparent head, studded with stainless-steel screws and embedded with microchips, sits immovable on its plinth. Unnervingly, its left eye looks real: lidless, it flickers in mute appeal as if someone were trapped inside. The Head of the Blue Chip II by Dianne Harris is one of several artworks commissioned by the Museum of Archaeology and Anthropology in Cambridge, UK, to complement the historical - and indeed prehistoric - artefacts that make up its current exhibition, Assembling Bodies.

Harris's head speaks of a possible future in which the mind might become as readable as your computer's hard drive. Such a transformation would surely take place under academic scrutiny. But how can we know of the past changes in belief that have shaped our view of the human body, such as those that led our Bronze Age ancestors to cease burying dead bodies and instead cremate them?

Scholars in different disciplines from the universities of Cambridge and Leicester, UK, have been funded by the Leverhulme Trust to explore these and other questions; Assembling Bodies is the publicly visible outcome. Curators Anita Herle, Mark Elliott and Rebecca Empson have brought ancient and modern cultural and scientific artefacts together with contemporary artists' responses to perennial questions about our material being. Clustered around seven themes, the exhibits, many loaned by other institutions, range from classical sculptures to a model of DNA, and from anatomical drawings and scientific instruments to an installation of string bags from Papua New Guinea.

The exhibition's section on genealogies contains one of the 119 volumes of the printed 'library' of the human genome commissioned by the Wellcome Trust. We see that attempts to codify human kinship in written form are not new, with a display of John Speed's early seventeenth-century Bible open at the genealogy he drew to link Adam to the Virgin Mary.

Measurement and classification were the foundations of anthropology as a professional discipline, and the museum draws on its own collections to show how the drive to define racial and psychological types could be subverted by its own methods. Alfred Cort Haddon's 1898 expedition to the Torres Strait islands between Australia and Papua New Guinea reported that, similar to modern geneticists, they found larger variations in physical measurements within the community of islanders than between the islanders and the expedition members. The sculptor Marguerite Milward made a collection of portrait busts in the 1930s to illustrate different Indian races, castes or tribes. She seems complicit with both colonial and Indian elites in justifying social stratification; yet standing in front of the pallid plastercasts, their individuality is what sticks in the mind.

What can and cannot be done with bodies is constrained by changing laws and customs. An Act for Preventing the Horrid Crime of Murder in Britain in 1751 used the threat of anatomical dissection as a deterrent to homicide.

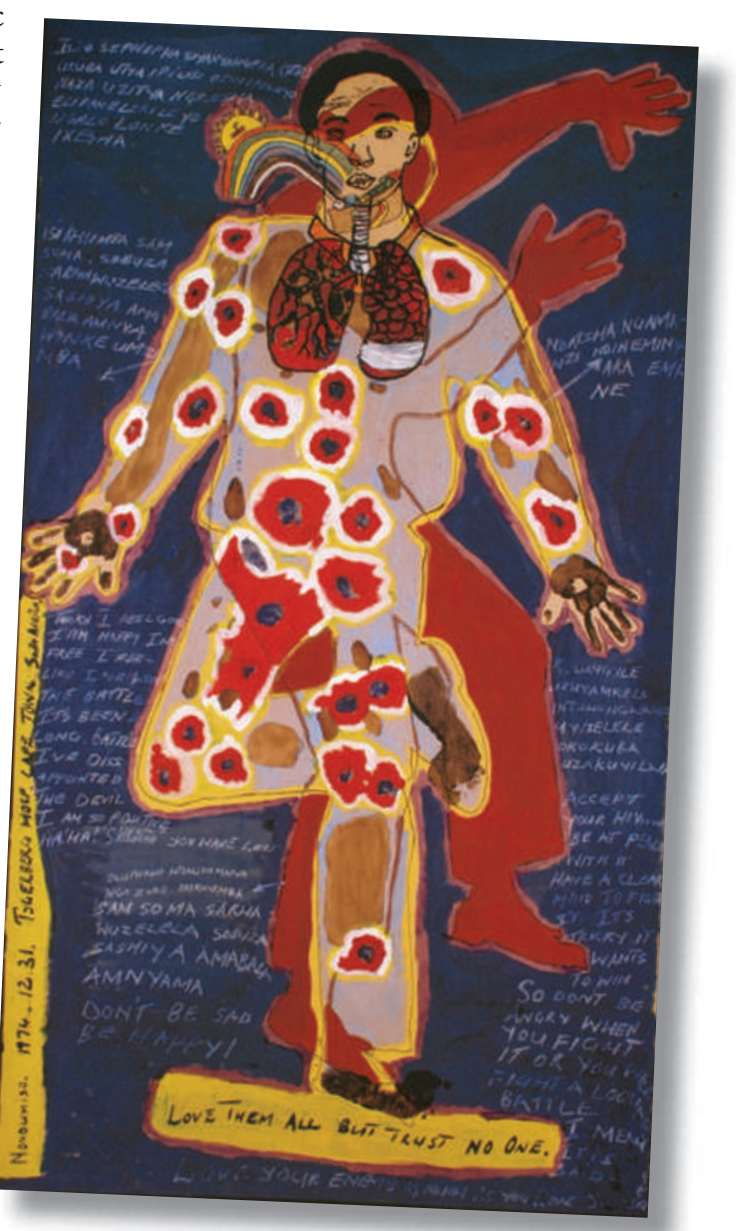

South African artist Nondumiso portrays her experience of living with HIV in Body-map (2003). 